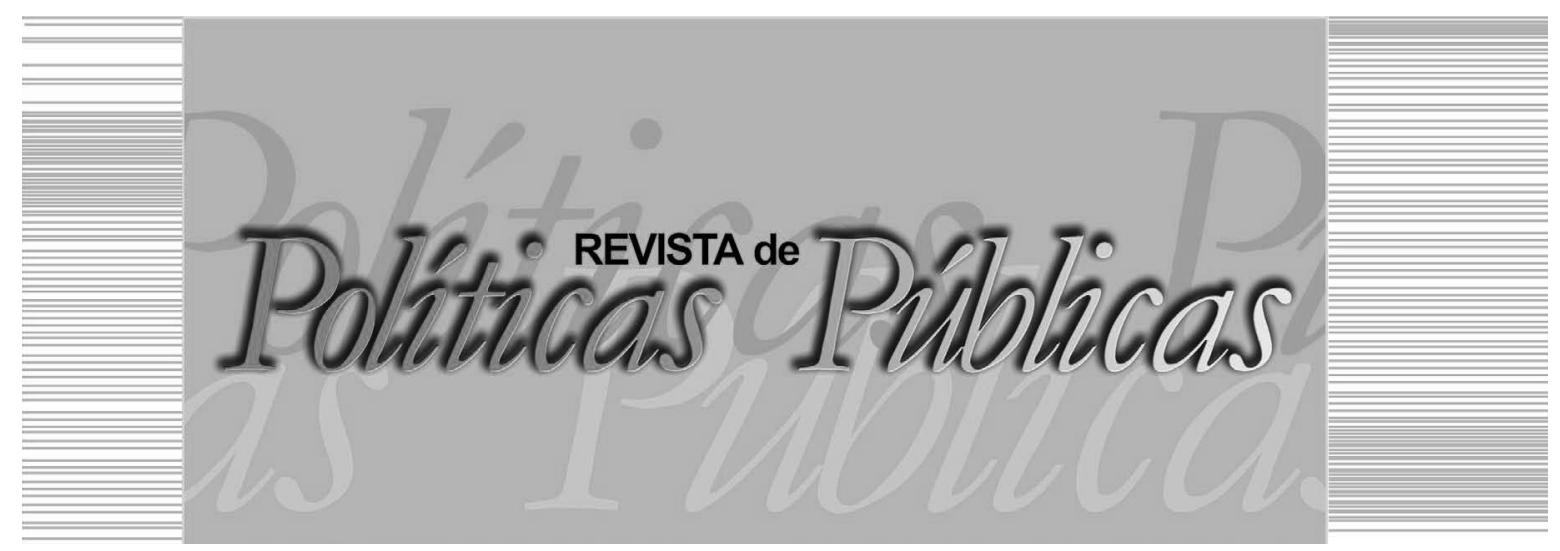

\title{
O LEGISLATIVO E O GERENCIALISMO NA GESTÃO DE PESSOAS DA ADMINISTRAÇÃO PÚBLICA
}

\author{
Joyce Frade Machado \\ José Carlos Jesus Lopes ${ }^{2}$ \\ Danielle Bertolino de Macedo Verão ${ }^{3}$ \\ Maira Sônia Camacho ${ }^{4}$ \\ Talita Guimarães de Oliveira Ferreira ${ }^{5}$
}

\section{Resumo}

As políticas de gestão de pessoas no serviço público podem ser consideradas matérias essencialmente abordadas durante todo o período histórico da Administração Pública. Além disso, há de se considerar que o Poder Executivo, ao promover suas ações, deve observá-las de forma vinculada às Leis. Nesse sentido, este artigo objetiva identificar na legislação federal que trata do tema políticas de gestão de pessoas, elementos que ratifiquem a perspectiva relacio-

${ }^{1}$ Matemática, Mestranda em Administração Pública pela Universidade Federal de Mato Grosso do Sul (UFMS). E-mail: jfradem@yahoo.com.br

2 Economista e Administrador, Doutor em Meio Ambiente e Desenvolvimento pela Universidade Federal do Paraná (UFPR), Professor do Programa de Mestrado Profissional em Administração Pública em Rede (PROFIAP) e do Mestrado Profissional de Eficiência Energética e Sustentabilidade (PPGES)/UFMS. E-mail: dejesusprofiap@gmail.com

3 Administradora, Mestranda em Administração Pública pelo PROFIAP/UFMS. E-mail: danibmacedo@gmail.com

4 Veterinária, Mestranda em Administração Pública pelo PROFIAP/UFMS. E-mail: mairacamacho1970@gmail.com

5 Administradora, Mestranda em Administração Pública pelo PROFIAP/UFMS. E-mail: taliferreira@gmail.com / Universidade Federal de Mato Grosso do Sul - UFMS: Av. Senador Filinto Müller, 1555, Unidade 10-A, Cidade Universitária Campo Grande - MS. CEP: 79070-900. 
nada à Nova Gestão Pública, a partir da promulgação da Constituição Federal de 1988. Para isso, faz uma pesquisa bibliográfica, com uma abordagem qualitativa, sobre os arranjos legais que tratam e disciplinam o tema. Conclui que há legislações promulgadas na perspectiva de colocar em prática o modelo gerencial, possibilitando melhoria no desenvolvimento do servidor e na qualidade da prestação do seu serviço.

Palavras-chave: Administração pública, políticas de gestão de pessoas, administração pública gerencial.

\title{
LEGISLATIVE AND MANAGERIALISM IN PEOPLE MANAGEMENT OF PUBLIC ADMINISTRATION
}

\begin{abstract}
Personnel management policies in the public service can be considered as a matter, essentially addressed during the entire historical period of Public Administration. In addition, it must be considered that the Executive Power, in promoting its actions, must observe, in a linked way, the Laws. In this sense, this article aims to identify in the federal legislation that deals with the topic of people management policies elements that ratify the perspective related to the New Public Management, from the promulgation of the Federal Constitution of 1988. For this, it is necessary a bibliographic research, With a qualitative approach, on the legal arrangements that treat and discipline the theme. It was concluded that there are legislations promulgated with the perspective of putting into practice the managerial model, enabling improvement in the development of the server and the quality of the provision of its service.

Key words: Public administration, people management policies, management public administration.
\end{abstract}

\section{INTRODUÇÃO}

Ao se recorrer à história da Administração Pública Brasileira, constata-se a latente preocupação com a adequada política de gestão de pessoas. (LONGO, 2007). Do Patrimonialismo para o Burocratismo e deste para o Gerencialismo, o foco encontra-se sempre em quem pratica as funções públicas; seja com ênfase nos processos internos - burocracia (MATIAS-PEREIRA, 2009), seja a ênfase no atendimento às necessidades do cliente cidadão. (PEREIRA, 1998).

No modelo da Nova Gestão Pública, “[...] a gestão de Recursos Humanos, a partir da Reforma do Estado desenvolvida no atual governo, equivale a uma verdadeira revolução silenciosa." (BRASIL, 2002, p. 10). 
Além disso, sabe-se que o Poder Executivo, ao promover suas ações, deve observá-las de forma vinculada às Leis, aos Regulamentos e aos Decretos. Isso posto, este artigo objetiva identificar na legislação federal que trata do tema políticas de gestão de pessoas, elementos que ratifiquem a perspectiva relacionada ao Gerencialismo, a partir da promulgação da Constituição Federal (CF) de 1988.

\section{APORTES TEÓRICOS}

\subsection{A gestão de pessoas do patrimonialismo ao modelo burocrático}

Durante o Brasil Colonial, perpassando pelo Brasil Império e pela República Velha, formalizaram-se ações e práticas patrimonialistas, advindas, sobretudo, dos traços culturais dos portugueses. Essa administração baseava-se na utilização dos cargos públicos, com fins clientelistas e de barganha política. Assim, entende-se por patrimonialismo, a inépcia do governante em diferenciar o que era bem público, do privado. Além disso, o Estado é identificado como uma extensão do poder do soberano, atuando por meio do nepotismo e da corrupção. (PEREIRA, 1998). A prática do nepotismo se dá, por exemplo, com o favorecimento de parentes ou amigos, preferencialmente, no que tange à ocupação de cargos públicos, ou ainda, quando o funcionário público age em benefício próprio e de seus interessados. (BOBBIO; MATEUCCI; PASQUINO, 1998). É nesse ambiente que se potencializa a prática da corrupção, que passa a ser definida como a oferta ou promessa de vantagem indevida a funcionário público, para determiná-lo a praticar, omitir ou retardar ato de ofício legal. (BRASIL, 1940).

Nesse contexto, também se insere o conceito de coronelismo, que pode ser compreendido como sendo um sistema político nacional, baseado em barganhas entre o governo e os coronéis, em que o primeiro cede o controle dos cargos públicos ao segundo, em troca de apoio na forma de votos. Também há o clientelismo, como aquele tipo de relação entre atores políticos, que envolve concessão de benefícios públicos, como exemplo, de empregos, e outros, em troca de apoio político, também manifestado no voto. (CARVALHO, 1997).

A partir da década de 1930, principalmente, com a ascensão de Getúlio Vargas ao poder, é iniciada uma grande empreitada no combate aos comportamentos patrimonialistas radicados na Admi- 
nistração Pública brasileira até aquele momento. Ideais e princípios de organização democrática passam a incorporar a esfera pública e a sociedade brasileira, tornando-se imprescindível a adoção de novos modelos de gestão pública em detrimento da continuidade do patrimonialismo. (PEREIRA, 1998).

É, assim, implantada então, a Administração Burocrática Estatal, fundamentada no modelo burocrático de Weber (1991), tendo como objetivo a determinação de um conjunto de procedimentos legais para ordenação racional e eficiente do espaço institucional das organizações públicas: formalização das funções e atividades administrativas; unidade de comando baseada na hierárquica; centralização de poder; profissionalismo suscitado pelo desenvolvimento de competências e habilidades administrativas, possibilitando, ainda, a formação de administradores altamente capacitados; impessoalidade na gestão pública; configuração organizacional norteada na estrutura piramidal de cargos e funções e estabelecimento de rotinas pouco flexíveis e processos administrativos subordinados às normas, processos e regras de controle. (PEREIRA, 1998).

A Burocracia propõe os princípios de legalidade, impessoalidade, regras formais e universais de conduta, como basilares, tanto na ação dos funcionários quando executam suas funções públicas, bem como na estruturação das carreiras públicas, envolvendo os processos de recrutamento, promoção, avaliação e controle de seus atos e omissões. (AZEVEDO; LOUREIRO, 2003).

Mais especificamente na área de pessoal, a Constituição Federal de 1934 introduz o princípio de mérito, em seu art. $170^{\circ}$, parágrafo $2^{\circ}$, com a exigência de concurso público de provas ou títulos para a primeira investidura nos postos de carreira das repartições administrativas. (BRASIL, 1934). Objetivando a profissionalização dos recursos humanos, foi instituída a Lei n. ${ }^{\circ} 284$, de 28 de outubro de 1936, de Reajustamento dos Quadros do Serviço Público Civil, cujos princípios balizadores seriam a formação de carreiras para funcionários civis federais, a divisão das carreiras e classes profissionais, o aperfeiçoamento do serviço público e as normas para o profissional da administração pública (BRASIL, 1936).

Surge então o Departamento Administrativo do Serviço Público (DASP) - com o Decreto - Lei no 579, de 30 de julho de 1938; suas principais funções se situavam em estabelecer uma maior integração entre os diversos setores da administração pública e, ade- 
mais, promover uma seleção e aperfeiçoamento do pessoal administrativo, por meio da adoção do sistema de mérito, determinante para dirimir a sobreposição dos interesses privados e político-partidários na ocupação dos empregos públicos, marcada pelas práticas patrimonialistas. (BRASIL; CEPEDA; MEDEIROS, 2014).

Destarte, o DASP possibilitaria a supervisão da administração pública, a formação de pessoal para os altos escalões do serviço público, a definição das escalas de salários para o setor público e, devido a isso, obteria certo êxito, pois as características patrimonialistas ainda se mantinham nos eixos inferiores da administração, com suas práticas clientelistas e nepotistas. (MARTINS, 1997).

Com o advento do Decreto Lei $n^{\circ}$. 200, de 25 de fevereiro de 1967, intentou-se a desburocratização a partir da possibilidade de contratação, na Administração Indireta, de servidores ingressantes sem concurso público. $\mathrm{O}$ objetivo residia na construção de um quadro de pessoal bem remunerado e bem capacitado. No entanto, a tentativa fracassou pelo fato de o resultado ser a continuidade das práticas patrimoniais com a contratação não por mérito, mas pelo nepotismo e enfraquecimento do núcleo estratégico do Estado. (PEREIRA, 1998).

Isso porque, ao longo da passagem dos governos seguintes, o que se instituiu foi a seguinte dinâmica no setor de pessoal: para os altos escalões da administração pública foi estabelecida a admissão mediante concurso público, planos de carreira e promoções baseados na meritocracia; entretanto, para os escalões médios e inferiores, a admissão mantinha-se de modo clientelista e as promoções baseadas apenas no tempo de serviço. (VASCONCELOS, 2002).

Mas, ainda que a Administração Pública Burocrática procurasse gerar ambientes favoráveis à meritocracia, competência, profissionalismo e formalização das relações de trabalho, surgiram disfunções burocráticas, destacando-se, entre elas, o excesso de autoritarismo, a consolidação de uma classe tecnocrática, a ineficiência, a ineficácia, os atrasos, confusões e privilégios. (VASCONCELOS, 2002). Por esses motivos, a Administração Burocrática Estatal já não respondia mais às demandas da sociedade e, por isso, em 1995, foi publicado o Plano Diretor da Reforma do Aparelho do Estado (PDRAE), dando início, no Brasil, à Reforma Gerencial do Estado. 


\subsection{Modelo gerencial de pessoas da administração pública}

A Reforma Gerencial do Estado foi iniciada pelo Ministério da Administração Federal e Reforma do Estado (MARE), que existiu entre 1995 e 1998, durante o primeiro governo de Fernando Henrique Cardoso. (PEREIRA, 1998). Um dos objetivos globais da Reforma Gerencial era aumentar a governança do Estado, ou seja, aumentar a sua capacidade administrativa de governar com efetividade e eficiência, voltando a ação dos serviços do Estado para o atendimento dos cidadãos (PDRAE, 1995).

Para Pereira (1998), a Administração Pública Gerencial, ou Nova Gestão Pública, tem como principais objetivos: aprimorar as decisões estratégicas do governo e da burocracia; promover a eficiência do setor público; garantir autonomia e capacitação gerencial do administrador público; e certificar a democracia por meio da prestação de serviços públicos voltados para o cidadão-cliente e controlados pela sociedade.

Assim, a Reforma Gerencial no Brasil aprofunda e renova a Administração Burocrática, propondo uma forma mais flexível e descentralizada de administrar os recursos humanos e definindo um novo perfil para o servidor público. (PEREIRA, 1998). A Nova Política de Recursos Humanos, um dos projetos adicionais do Plano Diretor, prioriza a carreira dos servidores públicos do núcleo estratégico do Estado e inclui quatro elementos básicos: a política de concursos; a política remuneratória das carreiras de Estado; a reorganização das carreiras; e a política de capacitação (BRASIL, 1997).

Nesse contexto, a política de recursos humanos buscou conciliar a mudança desejada do perfil e da qualificação dos recursos humanos às restrições fiscais. Novos conceitos sobre profissionalização permitiram que a capacitação permanente dos servidores fosse intensificada. E com relação à política de remuneração, a partir de 1995, o governo passou a praticar aumentos diferenciados, buscando corrigir distorções entre o setor público e o setor privado, conseguindo, assim, atrair novos servidores para as carreiras de Estado - para as quais foram organizados concursos anuais de ingresso. (PACHECO, 2014).

Outra importante política de Gestão de Pessoas, desenvolvida no modelo gerencialista, foi a avaliação de desempenho individual, que se caracteriza por um processo iniciado com o planejamento 
das ações a serem medidas e finalizado com a comparação entre o executado e o planejado. (GUIMARÃES; NADER; RAMAGEM, 1998). Além disso, no Governo de Fernando Henrique Cardoso, outras medidas foram implementadas na tentativa de consolidar o Modelo Gerencial na Administração Pública em relação à Gestão de Pessoas.

Em seguida, no governo de Luiz Inácio Lula da Silva, também foram estabelecidas algumas medidas que remetem às características do modelo gerencialista, voltadas à Gestão de Pessoas, tais como: Lançamento do Plano de Gestão para um Brasil de Todos (interrompido a partir de 2004) e instituição do Programa Nacional de Gestão Pública e Desburocratização (GESPÚBLICA), Intensificação de programas de capacitação, com destaque para ações de qualificação dos gestores públicos federais na área de avaliação e monitoramento. (SILVA; MARIN, 2013).

\subsection{O papel da legislação em gestão de pessoas no modelo gerencial da administração pública}

O Poder Legislativo, conforme determina a Constituição Federal (CF), possui como função prevalente a elaboração de leis, em sentido amplo, com o objetivo de regulamentar as várias relações existentes no nosso Estado e fora dele. Nesse caso, é importante destacar que, conforme inciso II, do art. $5^{\circ}$ da CF de 1988, "[...] ninguém será obrigado a fazer ou deixar de fazer alguma coisa senão em virtude de lei." (BRASIL, 1988), ou seja, se não houver lei em vigor capaz de vincular ao ato empregado, não há que se falar em proibição, obrigação, penalidade, vinculação, impedimento, imposição, encargo, entre outras.

Entretanto, esse direito não contempla as atividades exercidas pela Administração Pública, pois conforme art. $37^{\circ}$ da Carta Magna, a administração pública direta e indireta obedecerá, inclusive, ao princípio de legalidade, em que não poderá exercer suas atividades de forma discricionária, ou seja, deverá atuar em conformidade com a lei.

Pode-se inquirir, portanto, se a Administração Pública, que vem tentado implantar os fundamentos da Nova Gestão Pública Gerencial, atua de forma vinculante à lei e se essa lei é um ato jurídico emanado do Poder Legislativo, na sua atuação primária, que deve 
vislumbrar, no processo de formulação das leis, a efetividade do modelo Gerencial a ser conduzido pelo Governo de Estado.

\section{METODOLOGIA}

Para o presente artigo foi empregada a pesquisa do tipo descritivo-exploratória, com uma abordagem qualitativa, a partir da análise de documentos. A natureza qualitativa facilita a verificação e análise do fenômeno, possibilitando maior conhecimento sobre o tema, e envolvendo a obtenção de dados descritivos sobre o contexto estudado. (GODOY, 1995). Já a análise de documentos, segundo Sá Silva, Almeida e Guindani (2009), é quando o pesquisador se utiliza de documentos a fim de obter informações que servirão de base para sua investigação. Baseado nisso, os documentos analisados foram algumas leis federais (complementares e ordinárias) que tratam, no sentido geral, da administração de pessoas no serviço público federal, promulgadas a partir da atual CF de 1988.

Em princípio, foram feitos levantamentos na página oficial do Portal da Legislação do Governo Federal ${ }^{1}$ de todas as leis complementares e ordinárias que tratavam sobre o tema servidores públicos, promulgadas a partir da CF de 1988. Em seguida, descartaram-se todas as leis que versavam unicamente sobre reajustes salariais, alterações de atribuições, nomenclaturas e plano de carreira de alguns cargos e aposentadorias especiais de alguns servidores em específico. Na verdade, o intuito para essa pesquisa foi selecionar legislações que abordassem o gerenciamento de recursos humanos do Poder Executivo, sem se restringir a uma determinada carreira.

Nesse contexto, as legislações selecionadas foram: Lei $\mathrm{n}^{\circ}$ 8.027, de 12 de abril de 1990, Lei $\mathrm{n}^{\circ}$ 8.112, de 11 de dezembro de 1990; Lei $\mathrm{n}^{\circ}$ 8.140, de 28 de dezembro de 1990; Lei ${ }^{\circ} 8.745$, de 9 de dezembro de 1993; Lei ${ }^{\circ}$ 9.962, de 22 de fevereiro de 2000; Lei $\mathrm{n}^{\circ} 11.784$, de 22 de setembro de 2008; Lei ${ }^{\circ} 12.618$, de30 de abril de 2012; Lei n 12.990, de 9 de junho de 2014; e Lei Complementar $\mathrm{n}^{\circ} 152$, de 3 de setembro de 2015. Deve-se destacar que não foram selecionados Decretos, pois esse instrumento legal possui a finalidade de regulamentar leis que já se encontram em vigência. Também não foram selecionadas Medidas Provisórias, pois, nesse caso, elas são editadas pelo Presidente do Poder Executivo, e, possivelmente, convertidas em lei. 
Como o propósito da pesquisa foi identificar na Legislação Federal, que trata de tema políticas de gestão de pessoas, elementos que ratifiquem a perspectiva relacionada ao Gerencialismo a partir da promulgação da CF de 1988, a habilidade utilizada foi a capacidade de investigar os aspectos qualitativos das leis selecionadas e confrontar esses aspectos com preceitos teóricos.

\section{RESULTADOS E ANÁLISES}

Inicialmente faz-se uma análise da Lei 8.027/1990, cujo propósito é a definição de regras de conduta profissional do funcionário público, seja ele da Administração Direta ou Indireta; apresenta, portanto, os deveres dos servidores públicos, as tipologias de faltas administrativas e respectivas ações punitivas, além de outras orientações formais. (BRASIL, 1990a).

Nesse modelo, o servidor público pauta sua conduta pelas normas legais previamente estabelecidas, não restando a possibilidade de desviar-se por vontade pessoal ou de seu chefe superior, muito menos agir com discricionariedade sobre seus subalternos. (AZEVEDO; LOUREIRO, 2003). Sob a ótica gerencialista, não foi encontrado nenhum aspecto coincidente em seu corpo textual.

Já a Lei $n^{\circ}$ 8.112/1990 estabelece o Regime Jurídico Único dos Servidores Públicos Civis da União, autarquias e das fundações públicas federais. (BRASIL, 1990b). Nota-se que nesse rol estão excluídas as empresas públicas e sociedades de economia mista que se sujeitam ao regime jurídico próprio das empresas privadas, consoante art. $173^{\circ}$ da CF. (BRASIL, 1988).

Observa-se, nessa lei, a presença de princípios basilares do Gerencialismo, a saber: seus arts $20^{\circ}, 121^{\circ}$ e $132^{\circ}$ disciplinam sobre a responsabilização do servidor quanto aos seus atos no exercício da função pública. A responsabilidade, inciso $\mathrm{V}$ do art. $20^{\circ}$, é critério de avaliação de estágio probatório do servidor investido em cargo público, ou seja, sua ausência incorre em exoneração (dispensa) do cargo ocupado. $\mathrm{O}$ art. $121^{\circ}$ reforça a culpabilidade em suas vertentes penal, civil e administrativa, pelo exercício irregular das suas atribuições, e o art. $132^{\circ}$ estabelece a aplicação de demissão para os casos em que ocorrer crimes contra a Administração Pública, tais como a aplicação irregular do dinheiro público e a corrupção. 
Nessa vertente de responsabilização, o objetivo do legislador remete-se à noção de Accountability - entendida como a obrigação de subordinar-se às leis regulatórias e à fiscalização e controle interno e externo, referentes aos âmbitos institucionais e de órgãos fiscalizatórios. Da participação dos cidadãos resulta mais uma forma de controle social. (CAMPELO, 2010).

Pertinente ao investimento permanente em qualificação dos servidores com fins à efetiva valorização dos processos de trabalho e atingirem perfil profissional esperado (BRASIL, 2002), destaca-se $\mathrm{o}$ art. $81^{\circ}$, que trata da concessão de licença para capacitação, e o art. $96^{\circ}$-A, que autoriza o afastamento do exercício do cargo efetivo para participação em Programas de Mestrado e Doutorado para capacitação profissional. Ainda que inseridos na Lei analisada por leis posteriores, expressam a vontade do legislador em unificar, em toda a Administração Pública onde couber a Lei $n^{\circ}$ 8.112/1990, as ações de capacitação e qualificação profissional visando a oferta de "[...] mais e melhores serviços aos cidadãos." (BRASIL, 2002, p. 9).

No intuito de valorizar os servidores que efetivamente oferecem qualidade de atendimento ao cliente cidadão, aponta-se o art. $237^{\circ}$, por oferecer prêmios, medalhas, diplomas de honra ao mérito, condecoração e elogios pela apresentação de ideias, inventos ou trabalhos que favoreçam a produtividade e a redução de custos - a eficiência, um dos principais preceitos do Gerencialismo (PEREIRA, 1998), caracterizada como a busca da paridade entre custos e benefícios nas políticas públicas aplicadas pelo setor público. (CAMPELO, 2010).

Em linhas gerais, são identificadas características do modelo burocrático de administração na Lei ${ }^{\circ} 8.112 / 1990$, por se tratar de normas, regulamentos, prescrições, procedimentos e modus operandi do regime jurídico dos servidores públicos federais. (BRASIL, 1990b). Trata-se do ponto de partida para a organização e gestão racional e eficiente da máquina pública. (WEBER, 1991). No entanto, considerando o contexto político administrativo do ano dessa normativa, é possível destacar traços da nova política de recursos humanos, norteada pelo Gerencialismo.

Avançando, trata-se agora da Lei ${ }^{\circ} 8.140 / 1990$. O seu objetivo foi a criação da Escola Nacional de Administração Pública (ENAP), em substituição à Fundação Centro de Formação do Servidor Público (FUNCEP). Em se tratando das orientações estratégicas 
da política de recursos humanos da Administração Pública Gerencial, essa Lei atende às expectativas, pois com a criação dessa Escola de Governo buscou-se a formação e o desenvolvimento dos servidores públicos em todas as esferas de Estado, por meio da promoção e a disseminação de pesquisas, de publicações técnicas e produções científicas, da capacitação do gerente público, da oferta de cursos de Pós-graduação latu sensu e do incentivo às ações inovadoras, como os prêmios por inovação na gestão pública. (ESCOLA NACIONAL DE ADMINISTRAÇÃ̃ PÚBLICA, 2016).

A Lei ${ }^{\circ} 8.745 / 1993$ regulamenta a contratação temporária na Administração Pública para atender à necessidade temporária de excepcional interesse público, como por exemplo: calamidade pública, recenseamento, contratação de professor substituto, entre outras. Em 2008 essa lei foi modificada para regulamentar a contratação de temporários em situações análogas, quando da criação de órgãos ou entidades ou da definição de novas atribuições para aquelas já existentes, para fazer frente à necessidade de profissionais em quantidade e com qualificações características de processos de implantação ou de transição. Também foram autorizadas as contratações temporárias, quando houver aumento transitório no volume de trabalho, para elevar os padrões de serviço prestados à população.

Uma Administração Pública mais eficiente e voltada para atender os anseios do cidadão é um dos objetivos globais da Reforma Gerencial (BRASIL, 1995), por isso, pode-se entender que a Lei $\mathrm{n}^{\circ} 8.745 / 1993$ apresenta características gerencialistas, pois essa legislação trouxe mais flexibilidade e autonomia para os órgãos públicos, visto que permite seleção por processo simplificado.

A Lei ${ }^{\circ}$ 9.962/2000 disciplina o regime de emprego público do pessoal da Administração Federal direta, autárquica e fundacional, determinando que a relação de trabalho seja regida pela Consolidação das Leis do Trabalho (CLT). (BRASIL, 2000). Para esse caso, o Plano Diretor de Reforma do aparelho do Estado cita que a rigidez da estabilidade assegurada aos servidores públicos civis impede a adequação dos quadros de funcionários às reais necessidades do serviço e dificulta a cobrança de trabalho. Com base nisso, a referida lei também apresenta características gerencialistas, ao permitir a flexibilização das relações de trabalho. (PEREIRA, 1998).

Dando continuidade, a Lei ${ }^{0} 11.784 / 2008$ dispõe sobre a reestruturação do Plano Geral de Cargos do Poder Executivo (PGPE) 
e determina o Plano Especial de Cargos e o Plano de Carreiras de diversos órgãos e entidades. Essa Lei estabelece uma sistemática para avaliação de desempenho dos servidores da Administração Pública Federal direta, autárquica e fundacional. (BRASIL, 2008).

Salienta-se que o modelo gerencial propõe uma Nova Política de Recursos Humanos que priorize a carreira dos servidores públicos do núcleo estratégico do Estado e implemente a política de concursos, a política remuneratória das carreiras de Estado, a reorganização das carreiras e a política de capacitação. (BRASIL, 1997). Além disso, o modelo gerencialista introduz a avaliação de desempenho individual, que se caracteriza por um processo, iniciado com o planejamento das ações a serem medidas, e finalizado com a comparação entre o executado e o planejado. (GUIMARÃES; NADER; RAMAGEM, 1998).

Assim, fica claro que a Lei $\mathrm{n}^{0} 11.784 / 2008$ possui aspectos do gerencialismo, pois no seu art. $7^{\circ}$-A institui a gratificação de desempenho do Plano Geral de Cargos do Poder Executivo (GDPGPE), em função do desempenho individual do servidor e do desempenho institucional. E no decorrer da Lei apresenta, também, a gratificação de desempenho cabível aos diversos cargos e carreiras. Ademais, no capítulo II, art. $140^{\circ}$, a Lei institui uma sistemática para avaliação do desempenho dos servidores de cargos de provimento efetivo e dos ocupantes dos cargos de provimento em comissão da Administração Pública Federal direta, autárquica e fundacional, com o objetivo de ofertar serviços públicos mais eficientes. (BRASIL, 2008). Desse modo, ao apresentar o Plano de Cargos e o Plano de Carreiras de diversos órgãos e entidades, a Lei estabelece o incentivo à qualificação, por meio de Programas de capacitação para fins de progressão profissional.

Em síntese, identifica-se na Lei $\mathrm{n}^{0} 11.784 / 2008$ os seguintes princípios do modelo de Administração Gerencial: foco no fortalecimento das carreiras e na adequada política remuneratória (PEREIRA, 1998); definição de metas; construção de indicadores; avaliação, controle e reconhecimento sobre o desempenho e desenvolvimento de habilidades e competências, por meio do incentivo à qualificação. (CARNEIRO, 2010). Destaca-se que esses princípios são adotados com o objetivo de obter melhores resultados que atendam às necessidades dos cidadãos. 


\section{O LEGISLATIVO E O GERENCIALISMO NA GESTÃO DE PESSOAS \\ DA ADMINISTRAÇÃO PÚBLICA}

Já a Lei $\mathrm{n}^{\circ} 12.990 / 2014$ reserva aos negros $20 \%$ (vinte por cento) das vagas oferecidas nos concursos públicos para provimento de cargos efetivos e empregos públicos no âmbito da Administração Pública Federal, das autarquias, das fundações públicas, das empresas públicas e das sociedades de economia mista controladas pela União. (BRASIL, 2014).

O aspecto mais próximo ao gerencialismo observado nessa Lei refere-se ao aumento da governança por meio de políticas voltadas à igualdade de gênero e raça, aos direitos humanos e ao desenvolvimento social. (SILVA; MARIN, 2013). Diante do exposto, pode-se concluir, então, que essa Lei tem o objetivo de combater e minimizar os efeitos da discriminação histórica racial ao disponibilizar as cotas raciais em concursos públicos.

No entanto, a Administração Pública Gerencial tem como característica a meritocracia. E o concurso público foi institucionalizado com o objetivo de garantir que a Administração Pública possa prover seus cargos com as pessoas mais bem qualificadas, de acordo com o mérito e não por parentesco, ascendência, classe social ou cor da pele, de modo a gerar a eficiência administrativa e, por consequência, os melhores resultados à sociedade.

Nesse sentido, ainda que exista jurisprudência favorável a ações com critério racial, atente-se que as reservas de vagas para negros nos concursos públicos enfrentam "[...] muitos questionamentos acerca de uma possível afronta à meritocracia ou sobre a necessidade de conjugar suas diretrizes com critérios de renda." (SILVA; SILVA, 2014, p. 19), isso porque, após a classificação dos candidatos habilitados em determinado concurso público, a Administração Pública interferirá nessa classificação, beneficiando aqueles que se enquadraram dentro das cotas. (SILVA; SILVA, 2014). Analisando por essa vertente, a Lei no 12.990/2014 não apresenta, na sua integridade, características do gerencialismo.

A Lei ${ }^{\circ}$ 12.618/2012 instituiu o regime de Previdência Complementar para os servidores públicos federais titulares de cargo efetivo, pois, até então, todos os servidores eram amparados pelo regime próprio de Previdência do seu ente federativo empregador. (BRASIL, 2012). Do ponto de vista fiscal, a reestruturação previdenciária no serviço público foi necessária e essencial para a reforma do Estado, além disso, do ponto de vista social, o regime próprio era encarado como um sistema injusto e desequilibrado, em que o 
servidor se aposenta com um valor bem acima daquele recebido no setor privado. (BRASIL, 1995). Por isso, considera-se essa Lei essencialmente gerencialista.

Por fim, a Lei $\mathrm{n}^{\circ} 152 / 2015$, dispõe sobre a aposentadoria compulsória por idade, com proventos proporcionais, no âmbito da União, dos Estados, do Distrito Federal e dos Municípios, dos agentes públicos aos quais se aplica o inciso II do $\S 1^{\circ}$ do art. $40^{\circ}$ da CF. (BRASIL, 2015). Na área da Previdência Social, a Administração Gerencial objetiva garantir que as aposentadorias ocorram em idade razoável, evitando aposentadorias antes dos 60 anos, e que sejam proporcionais ao tempo de contribuição do servidor. (BRASIL, 1995). Nesse aspecto, pode-se concluir que essa Lei apresenta características gerencialistas, pois estabelece a aposentadoria compulsória aos 75 anos, com proventos proporcionais à contribuição realizada.

\subsection{Análise do papel do Poder Legislativo}

Diante do levantamento das características das legislações ordinárias e complementares sobre o tema gestão de pessoas, percebe-se o quanto o Poder Legislativo, na sua dimensão legislativa, é essencial "[...] para a operacionalização das mudanças pretendidas, de maneira a remover os constrangimentos existentes que impedem a adoção de uma administração ágil e com maior grau de autonomia, capaz de enfrentar os desafios do Estado moderno." (BRASIL, 1995, p. 49).

Verifica-se que alguns atributos do Gerencialismo têm sido observados na construção do aparato legal que norteia a Administração Pública, após a promulgação da CF de 1988. Por isso, pode-se entender que o Poder Legislativo tem contribuído com a trajetória histórica da Administração Pública, possibilitando introduzir os aspectos do gerencialismo.

Destaca-se, todavia, que seis das nove leis analisadas foram de iniciativas do Poder Executivo. Essa iniciativa é legitima, porém possibilita cogitar que o Poder Executivo é o mais interessado na mudança da Administração Pública. Além disso, relembre-se que a Reforma Gerencial no Brasil se iniciou a partir de 1995, por esse motivo faz sentido que a Lei ${ }^{0} 8.027 / 1990$ não possua características gerenciais. 


\section{CONCLUSÃO}

Levando-se em consideração que o objetivo deste artigo foi identificar na legislação federal, que trata do tema políticas de gestão de pessoas, elementos que ratifiquem a perspectiva relacionada ao Gerencialismo, conclui-se que várias legislações foram promulgadas na perspectiva de colocar em prática o modelo gerencial, possibilitando melhoria no desenvolvimento do servidor e na qualidade da prestação do seu serviço.

Durante o estudo, foi possível perceber que o tema gestão de pessoas no serviço público perpassa, de forma histórica, por demandas positivadas no nosso ordenamento legal, fazendo com que o Legislativo participe de forma ativa no aperfeiçoamento da Administração Pública.

Os resultados aqui obtidos ressaltaram que, apesar de não se incluir nessa análise as legislações que versavam, unicamente, sobre reajustes salariais e reestruturação de alguns cargos em específico, a Nova Política de Recursos Humanos, que foi um dos projetos adicionais do Plano Diretor, priorizava, inclusive, a política remuneratória das carreiras de Estado e a reorganização das carreiras (BRASIL, 1997). Isso comprova que houve ainda mais interação entre o Poder Executivo e o Poder Legislativo na tentativa de praticar o gerencialismo na Administração Pública Federal.

Nesse aspecto, a evolução da Administração Pública precisa ser considerada relevante para todos os envolvidos. Cabe considerar, ainda, que outras pesquisas podem ser desenvolvidas, entre elas a análise da regulamentação dessas leis e se, de fato, houve uma implantação satisfatória da filosofia da Nova Gestão Pública nos órgãos públicos que compreendem a Administração Pública.

\section{REFERÊNCIAS}

AZEVEDO, C. B. de; LOUREIRO, M. R. Carreiras públicas em uma ordem democrática: entre os modelos burocrático e gerencial. Revista do Serviço Público, Brasília, DF, ano 54, n 1, jan./mar. 2003. Disponível em: $<$ https://revista.enap.gov.br/index.php/RSP/article/ view/261>. Acesso em: 9 maio 2016.

BOBBIO, N.; MATTEUCCI, N.; PASQUINO, G. Dicionário de política. 11. ed. Brasília, DF: Ed. UnB, 1998. 
BRASIL, F. G.; CEPEDA, V. A.; MEDEIROS, T. B. O DASP e a formação de um pensamento político-administrativo na década de 1930 no Brasil. Revista Temas de Administração Pública, Araraquara, v. 9, n. 1, 2014. Disponível em:<http://seer.fclar.unesp.br/temasadm/ article/view/6961>. Acesso em: 11 maio 2016.

BRASIL. Constituição. Constituição da República Federativa do Brasil (de 16 de julho de 1934). Rio de Janeiro, RJ, 1934. Disponível em:<http://www.planalto.gov.br/ccivil_03/constituicao/ Constituicao34.htm>. Acesso em: 10 maio 2016.

. Constituição. Constituição da República Federativa do Brasil

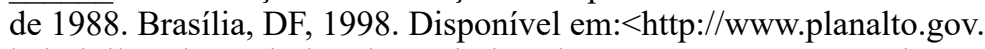
br/ccivil_03/Constituicao/Constituicao.htm>. Acesso em: 10 maio 2016.

. Ministério da Administração e Reforma do Estado. A Nova Política de Recursos Humanos, Brasília, DF, 1997. (Caderno MARE da reforma do estado, c. 11). Disponível em: $<$ http://www. escoladegestao.pr.gov.br/arquivos/File/Ministerio_do_Planejamento/ MARE/A_Nova_Politica_de_RH.pdf>. Acesso em: 10 maio 2016.

. Ministério do Planejamento, Orçamento e Gestão. Secretaria de Gestão. A Política de Recursos Humanos na Gestão FHC. Brasília, DF, 2002. (Coleção Gestão Pública). Disponível em: $<$ https://admufms. files.wordpress.com/2007/09/a-politicade-recursos-humanosna-gestaofhc.pdf $>$. Acesso em: 10 maio 2016.

. Presidência da República. Decreto-Lei no 2.848, de 7 de

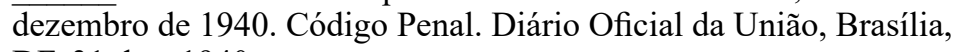
DF, 31 dez. 1940.

. Lei Complementar n. ${ }^{\circ} 152$, de 03 de setembro de 2015. Dispõe sobre a aposentadoria compulsória por idade, com proventos proporcionais, nos termos do inciso II do $\S 11^{\mathrm{o}}$ do art. 40 da Constituição Federal. Diário Oficial da União, Brasília, DF, 4 dez. 2015 .

. Lei n. ${ }^{\text {o } 284, \text { de }} 28$ de outubro de 1936. Reajusta os quadros e os vencimentos do funcionalismo público civil da União e estabelece diversas providencias. Diário Oficial da União, Brasília, DF, 30 out. 1936.

Lei n. ${ }^{\circ} 8.027$, de 12 de abril de 1990. Dispõe sobre

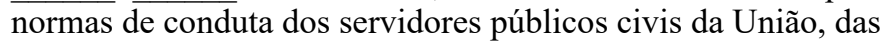
Autarquias e das Fundações Públicas, e dá outras providências. Diário Oficial da União, Brasília, DF, 13 abr. 1990a. 
. Lei n. ${ }^{\circ} 8.112$, de 11 de dezembro de 1990. Dispõe sobre o regime jurídico dos servidores públicos civis da União, das autarquias e das fundações públicas federais. Diário Oficial da União, Brasília, DF, 19 abr. 1990b.

. Lei n. ${ }^{\circ} 8.745$, de 09 de dezembro de 1993. Dispõe sobre a contratação por tempo determinado para atender a necessidade temporária de excepcional interesse público, nos termos do inciso IX do art. 37 da Constituição Federal, e dá outras providências. Diário Oficial da União, Brasília, DF, 10 dez. 1993.

. Lei n. ${ }^{\circ} 9.962$, de 22 de fevereiro de 2000. Disciplina o regime de emprego público do pessoal da Administração federal direta, autárquica e fundacional e dá outras providências. Diário Oficial da União, Brasília, DF, 22 fev. 2000.

Lei n. ${ }^{\circ} 11.784$, de 22 de setembro de 2008. Dispõe sobre a reestruturação do Plano Geral de Cargos do Poder Executivo PGPE ... Diário Oficial da União, Brasília, DF, 23 set. 2008.

. Lei n. ${ }^{\circ} 12.618$, de 30 de abril de 2012. Institui o regime de previdência complementar para os servidores públicos federais titulares de cargo efetivo, inclusive os membros dos órgãos que menciona; fixa o limite máximo para a concessão de aposentadorias e pensões pelo regime de previdência de que trata o art. 40 da Constituição Federal; autoriza a criação de 3 (três) entidades fechadas de previdência complementar .... Diário Oficial da União, Brasília, DF, 2 maio 2012.

. Lei n. ${ }^{\circ} 12.990$, de 09 de junho de 2014. Reserva aos negros $20 \%$ (vinte por cento) das vagas oferecidas nos concursos públicos para provimento de cargos efetivos e empregos públicos no âmbito da administração pública federal, das autarquias, das fundações públicas, das empresas públicas e das sociedades de economia mista controladas pela União. Diário Oficial da União, Brasília, DF, 10 jun. 2014.

$\overline{\text { Brasília, }} \overline{\mathrm{DF}, 1995}$

Plano Diretor da Reforma do Aparelho do Estado.

CAMPELO, G. S. B. Administração Pública no Brasil: Ciclos entre Patrimonialismo, Burocracia e Gerencialismo, uma Simbiose de Modelos. Ciência e Trópico, Recife, v. 34, n. 2, p. 297-324, 2010. Disponível em:<https://periodicos.fundaj.gov.br/CIC/article/ viewFile/871/592>. Acesso em: 23 maio 2016. 
CARNEIRO, M. F. S. Gestão Pública: o papel do planejamento estratégico, gerenciamento de portfólio, programas e projetos e dos escritórios de projetos na modernização da Gestão Pública. Rio de Janeiro: Editora Brasport, 2010.

CARVALHO, J. M. de. Mandonismo, coronelismo, clientelismo: uma discussão conceitual. Dados [Online], Rio de Janeiro, v. 40, n. 2, 1997. Disponível em: $<$ http://www.scielo.br/scielo.php?script=sci_arttext\&pi $\mathrm{d}=$ S0011-52581997000200003 >. Acesso em: 2 jun. 2016.

ESCOLA NACIONAL DE ADMINISTRAÇÃO PÚBLICA. Quem somos. Brasília, DF, [20--?]. Disponível em<http://www.enap.gov.br/ web/pt-br/quem-somos>. Acesso em: 23 jun. 2016.

GODOY, A. S. Pesquisa qualitativa - tipos fundamentais. Revista de Administração de Empresas, São Paulo, v. 35, n.3, p. 20-29, maio/jun. 1995. Disponível em: <http://www.scielo.br/pdf/rae/v35n3/a04v35n3. pdf $>$. Acesso em: 2 jun. 2016.

GUIMARÃES, T.; NADER, R.; RAMAGEM, S. Avaliação de desempenho de pessoal: uma metodologia integrada ao planejamento e à avaliação organizacionais. Revista de Administração Pública, Rio de Janeiro, v. 32, n. 6, nov./dez. 1998. Disponível em:<http:// bibliotecadigital.fgv.br/ojs/index.php/rap/article/view/7775>. Acesso em: 15 maio 2016.

LONGO, F. Mérito e flexibilidade: a gestão de pessoas no setor público. São Paulo: FUNDAP, 2007.

MARTINS, L. Reforma da Administração Pública e cultura política no Brasil: uma visão geral. Brasília, DF: ENAP, 1997. (Cadernos ENAP, n. 8). Disponível em:<http://repositorio.enap.gov.br/bitstream/1/239/1/ Caderno\%20ENAP\%2008.pdf $>$. Acesso em: 10 maio 2016.

MATIAS-PEREIRA, J. Curso de Administração Pública: foco nas instituições e ações governamentais. 2. ed. São Paulo: Atlas, 2009.

PACHECO, R. S. Política de recursos humanos para a reforma gerencial: realizações do período 1995-2002. Revista do Serviço Público, Brasília, DF, v. 53, n. 4, p. 79-106, 2014. Disponível em:<https://revista.enap.gov.br/index.php/RSP/article/view/295>. Acesso em: 23 maio 2016.

PEREIRA, L. C. B. Reforma do Estado para a cidadania: a nova política de recursos humanos. S. Paulo: Editora. 34, 1998.

SÁ-SILVA, J. R.; ALMEIDA, C. D; GUINDANI, J. F. Pesquisa documental: pistas teóricas e metodológicas. Revista Brasileira 
de História e Ciências Sociais, São Leopoldo, v. 1, n. 1, jul. 2009. Disponível em:<file:///C:/Users/Joyce/Downloads/6-14-1-PB.pdf>. Acesso em: 1 jun. 2016.

SILVA, F. L. S.; MARIN, P. Gestão de pessoas no governo de Luiz Inácio da Silva (Lula): Análise das políticas desenhadas e implementadas e de sua relação com o modelo de gestão pública do governo federal. In: CONGRESSO CONSAD DE GESTÃO PÚBLICA, 6., Brasília, DF, 2013. Anais... Curitiba: Gerência Executiva da Escola de Governo, 2013. Disponível em: $<$ http:// www.escoladegestao.pr.gov.br/arquivos/File/2013/V_CONSAD/ VI_CONSAD/160.pdf >. Acesso em: 1 jun. 2016.

, T. D.; SILVA, J. M. Reserva de vagas para negros em concursos públicos: uma análise a partir do Projeto de Lei 6.738/2013. Brasília, DF: IPEA, 2014. (Nota Técnica, n. 17). Disponível em: $<$ http://repositorio.ipea.gov.br/bitstream/11058/5781/1/NT_n17 Reserva-vagas-negros-concursos-publicos_Disoc_2014-fev.pdf $\$$. Acesso em: 25 jul, 2016.

VASCONCELOS, F. C. Racionalidade, Autoridade e Burocracia: as bases da Definição de um Tipo Organizacional Pós-Burocrático. In: ENCONTRO NACIONAL DE ESTUDOS ORGANIZACIONAIS, 2., 2002, Recife. Anais... Recife: Observatório da Realidade Organizacional: PROPAD/UFPE: ANPAD, 2002. Disponível em: $<$ http://www.anpad.org.br/admin/pdf/eneo2002-23.pdf $>$. Acesso em: 23 maio 2016.

WEBER, M. Sociologia. São Paulo: Ática, 1991.

\section{Nota}

${ }^{1}$ Disponível em: $<$ http://www.planalto.gov.br/legislacao>. 
